\title{
Exploring Public Responses to Government's COVID-19 Pandemic Policies
}

\author{
Brenna Drummond 1* \\ (1) 0000-0003-4123-0622
}

\section{Aysun Bozanta ${ }^{1}$}

\section{(1) 0000-0002-1768-6278}

${ }^{1}$ Ryerson University, CANADA

*Corresponding author: bdrummond@ryerson.ca

Citation: Drummond, B., \& Bozanta, A. (2022). Exploring Public Responses to Government's COVID-19 Pandemic Policies. Online Journal of Communication and Media Technologies, 12(2), e202212. https://doi.org/10.30935/ojcmt/11829

ARTICLE INFO

Received: 23 Dec 2021

Accepted: 25 Feb 2022

\section{ABSTRACT}

The ongoing pandemic of coronavirus disease 2019 (COVID-19) has challenged governments worldwide and approaches to combating the spread and maintaining livelihoods have ranged significantly. The purpose of the study is to a) investigate whether social media, specifically Twitter, can be used to identify topics of discussion regarding governments' COVID-19 policies, and; b) whether those discussions can be interpreted in a way that can support governments in making policy decisions. Real-time public responses to these policies are a matter of interest, as understanding the content of discussions and the attitudes expressed towards government approaches can support the development of more grounded solutions for large-scale policy issues. Latent Dirichlet Allocation (LDA) is used to identify topics of discussion alongside Valence Aware Dictionary for sEntiment Reasoning (VADER) sentiment analyzer. Text data from two different jurisdictions are used and examined side by side. The Oxford COVID-19 Government Response Tracker (OxCGRT) is used to standardize policy discussions. The results of the study found that: a) Individuals tweeted most frequently and most passionately about case and death rates in their jurisdictions. Particularly about the rates with respect to vulnerable populations, such as those in long term care, nursing homes, and health workers, and b) Tweets expressed frustrations with the communication, length of implementation, or lack of rationale behind policies, suggesting the way the policy is communicated and delivered impacts individuals' sentiments.

Keywords: topic modelling, sentiment analysis, Twitter, government policy, public response, COVID-19, OxCGRT

\section{INTRODUCTION}

Sub-national jurisdictions in Canada and the United States have been tasked with the design, implementation, communication, and enforcement of policy responses to the ongoing pandemic of coronavirus disease 2019 (COVID-19). Policy responses across jurisdictions vary greatly in terms of stringency and duration of imposition. Further, policy observance has been mixed, showing fluctuating degrees of compliance throughout policy stages and over extended time periods. Consequently, it is likely that individuals' experiences with COVID-19 in their region differ greatly. Personal experience is an important consideration for policy-makers when designing and communicating policy decisions given that observance to those policies necessitates individuals' willingness to comply.

The aim of this study is to examine public responses to the government's COVID-19 policies over time. Using data extracted from Twitter, specifically related to individuals engaging with their government on the policies their government has (or have not) implemented, the study aimed to answer the following questions:

1. What are the key topics present in the Ontario and New York Twitter data and what are the discussions within these topic groups?

Copyright $(2022$ by authors; licensee OJCMT by Bastas, CY. This article is an open access article distributed under the terms and conditions of the Creative Commons Attribution License (http://creativecommons.org/licenses/by/4.0/). 
2. What are the differences/similarities between topics identified in the Ontario and New York text data?

3. How does daily average sentiment expressed for identified topic groups change over time and do those changes (or little changes) have interpretable meaning?

4. What high-level observations can be made about governments' COVID-19 policies using Twitter data?

Twitter data was scraped from the jurisdictions of Ontario and New York. These specific regions were selected because of their size and differing political approaches. Daily sentiments are compared to policy indices designed and recorded by the Oxford COVID-19 Government Response Tracker (OxCGRT). Observations are made alongside additional metrics, such as case numbers and the number of deaths as a result of the disease. The appropriateness or effectiveness of the policies themselves with respect to combatting COVID-19 will not be within the scope of this study.

The contribution of this study can be summarized, as follows:

1. To the best of our knowledge, this is the first study that aims to understand and group the responses and discussions of citizens in different regions specifically to government COVID-19 policies using Twitter data.

2. Sentiment analysis was performed on the tweets shared by the public over a 14-month period of the pandemic, and topics were identified for different regions by LDA. The topics are concise, interpretable, repeatable, and correspond to specific events known throughout the pandemic.

3. This solution, which is developed by analyzing and grouping the Twitter data to understand the public's reactions to the COVID-19 policies of the government, can be implemented easily, quickly at a very low cost.

The rest of the paper is organized, as follows. Next section provides a brief discussion on the relevant literature on public attitudes towards the ongoing COVID-19 pandemic and studies using social media data. Then, we explain the collection of data and the description of the methods employed. After that we explore the results of the sentiment analysis and the topic modeling. We then discuss the study findings as they relate to policy communication. Finally, we present concluding remarks, the limitations of the study, and the future research directions.

\section{LITERATURE REVIEW}

A number of studies have aimed to investigate public attitudes expressed at some point over the ongoing COVID-19 pandemic (Sabat et al., 2020; Sibley et al., 2020) and identify the drivers behind those sentiments (Chen et al., 2021; Petherick et al., 2021). Research performed by Sibley et al. (2020) used response data surveyed from individuals before and after lockdown, discovering higher rates of national unity or patriotism in early pandemic stages, however, coupled with increasing reports of mental distress among participants. Further research by Petherick et al. (2021) used survey data and mobile tracking data to model individuals' compliance rates with their governments' COVID-19 policies, finding that policy fatigue impacts all individuals regardless of their demographic or socio-economic background. Many studies focus on a point in time and use survey data collected from individuals over that duration.

Giving the growing interest in the use of social media to examine public discourse, there are many studies that use social media and machine learning approaches to explore public sentiment. Social media platforms such as Facebook, Reddit, and Twitter have become popular sources for research related to public sentiment (Albalawi et al., 2017; Alnumay et al., 2021; Arpaci et al., 2020; Huto et al., 2014; Jelodar et al., 2020; Kaila \&Prasad, 2020; Kaminska et al., 2021; Müller et al., 2020; Roy et al., 2020; Sanders et al., 2021; Sarsam et al., 2021; Satu et al., 2021). Twitter has been found to be the most relevant source, particularly with respect to health-related communications (Albalawi et al., 2017). Hybrid approaches to natural language processing are common, wherein lexiconic and machine learning approaches are combined to optimize sentiment classification and/or topic exploration (Arpaci et al., 2020; Kaminska et al., 2021; Sarsam et al., 2021; Satu et al., 2021; Vashishtha \& Susan, 2021). Few used unsupervised methods exclusively (Müller et al., 2020), as most seek to enhance commonly used machine learning methods (Arpaci et al., 2020; Dey et al., 2020; Jelodar et al., 2020; Kaminska et al., 2021; Roy et al., 2020; Sanders et al., 2021; Satu et al., 2021). State-of-the-art approaches that achieve high accuracy or interpretable results used transformer models and/or neural 
networks (Dey et al., 2020; Kaminska et al., 2021; Müller et al., 2020; Sanders et al., 2021). Studies in this area of interest all share the issue of ground truth. Considering scraped social media data is not pre-labeled, approaches that have more definitive findings tended to have solutions with this limitation in mind. Those that did use pre-labelled data had their own problems with respect to the lack of domain-specificity.

In government, resources to build and execute state-of-the-art algorithms are scarce and difficult to obtain. Therefore, there is a need for cost and time-efficient approaches that may allow policy-makers to better understand real-time public response. What many studies lack is relevant and interpretable information about government policy that is specific to a domain and jurisdiction. High-level clustering tends to be observational and lack relevance. Further, while most frequent n-grams can help color a discussion, they do not reveal the more complex relationships between topics and subjects. For example, many individuals discuss the same topics, however discovering how they speak about the topic and with respect to what context is the challenge. The idea behind this study was to dig down on discussions related to COVID-19 policies within certain jurisdictions and identify concise topics and relationships that would support policymakers in understanding their audience quickly. Relevance of topics was the focus of this study in an effort to weed out terms that appeared frequently across the corpus (Sievert \& Shirley, 2014).

\section{METHODOLOGY}

The primary datasets that were used were scraped from Twitter using Twint ${ }^{1}$, a python library built explicitly for scraping Twitter data. Considering the scope of this study is focused on engagement with the government regarding COVID-19 policies within a specific jurisdiction, a list of government official handles and primary government entities was created alongside a list of key terms meant to capture COVID-19 policyrelated conversations. The idea behind scrapping tweets that were tweeted at a specific government official was to capture the thoughts of individuals within a specific jurisdiction. Because of the need to use certain key terms and handles, using geolocation would not be possible as geolocation (i.e., latitude and longitude) is available for only $1-2 \%$ of the tweets made 2 . Therefore, the pool of tweets to draw from would not be significant (less than a few hundred per day). Further, studies have shown that government leaders have more popularity and engagement on average than the institutions that they represent ${ }^{3}$. The Twitter handles specified included government officials that were either very central to the government decision-making process or were very public-facing. For Ontario, @ONgov, @ONThealth, @fordnation, @ONeducation, @JohnTory, @ONeconomy, @ONSocialService, @ONTatwork, and @ONsafety were used. These handles represent the Ontario Government's official account, Ontario Ministry of Health, Ontario's Premier, Doug Ford, Ministry of Education, Toronto Mayor, John Tory, Ministry of Economic Development, Job Creation and Trade, Ministry of Children, Community and Social Services, Ministry of Labour Training and Skills Development, and Ministry of the Solicitor General, respectively. For New York, @NYGovCuomo, @SenSchumer, @SenGillibrand, and @NYCMayor were used. These handles represent the former Governor of New York, New York's two senators, and the Mayor of New York. The limited number of government handles is due to the character limit Twint has in its search function. Required key terms included covid, coronavirus, virus, covid-19, and pandemic to cast a wide net. Over 530,000 and 6,500,000 tweets were collected for Ontario and New York, respectively, from March 1, 2020- June 1, 2021, and all of them are in English. Twint automatically scrapes information on a number of fields, however, for the purposed of this study-DateTime and Tweet fields were used.

It is important to note that Twitter was chosen as the platform to pull data from for two reasons: first, Twitter is more popular for government entities and officials to use when compared to Facebook 4 . And second, engagement on Twitter has more of a real-time culture-meaning that individuals go to express their thoughts and engage with others on a topic. After scraping, the tweets from each dataset underwent basic preprocessing steps. First, we cleared tweets of unnecessary content, such as links, punctuation, and digits. We removed user handles and hashtags along with emojis. Next, we removed stop words and extra white spaces, and lemmatized the texts. We checked the datasets for duplicates and N/As, both of which were

\footnotetext{
1 https://github.com/twintproject/twint

2 https://developer.twitter.com/en/docs/tutorials/tweet-geo-metadata.html

${ }^{3}$ https://www.ospi.es/export/sites/ospi/documents/documentos/redes-sociales/OECD_Social_Media_use_by_Governments.pdf

${ }^{4}$ https://www.ospi.es/export/sites/ospi/documents/documentos/redes-sociales/OECD_Social_Media_use_by_Governments.pdf
} 


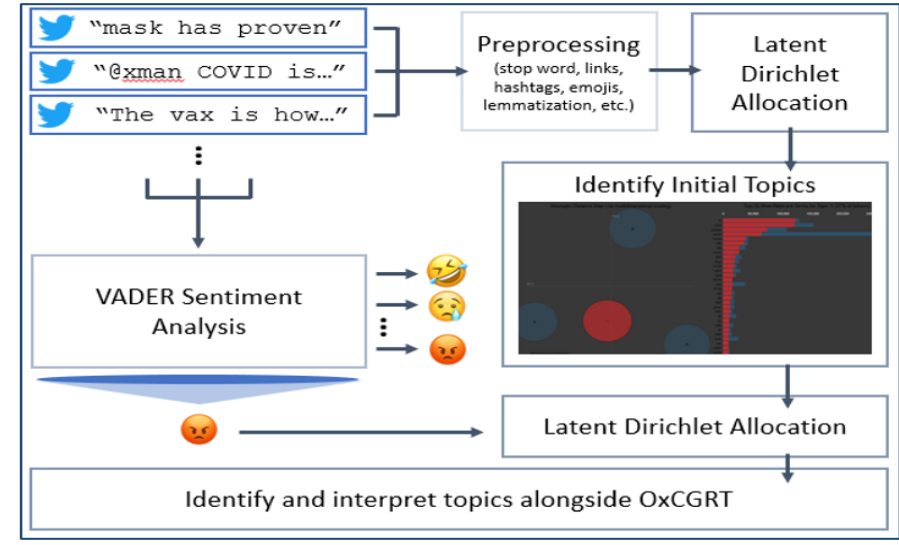

Figure 1. Pipeline process

removed for ease. After preprocessing steps, the Ontario set around 500,000 tweets and the New York set had 600,000 tweets.

We processed sentiments for each tweet by using VADER (Hutto \& Gilbert, 2014), recorded the compound score ${ }^{5}$ of each text, and removed those classified as being 'neutral'. The rationale for the removal of neutrals is that a neutral classification can mean the sentiment was truly neutral, but it can also mean that the text sentiment is indiscernible. It is worth noting that the text used to classify sentiment scores underwent less preprocessing, given better performance when punctuation, letter case, emojis, and non-lemma forms were used.

Latent Dirichlet Allocation (LDA) was applied to the fully processed tweets to identify discussion topics (Equation 1). The lowest perplexity score and largest log-likelihood were used to select the best fitting $\mathrm{k}$ number of topics for LDA.

$$
P(W, Z, \theta, \varphi, \alpha, \beta)=\prod_{j=1}^{M} P\left(\theta_{j} ; \alpha\right) \prod_{i=1}^{K} P\left(\varphi_{i} ; \beta\right) \prod_{t=1}^{N} P\left(Z_{j, t} ; \theta_{j}\right) P\left(W_{j, t} \mid \varphi_{z_{j, t}}\right)
$$

(Equation 1)

The investigation of sentiments within topics showed that tweets relating to covid-19 were over-archingly negative, even if just slightly so. This led to the question as to whether one would expect that tweets overall were negative, given that Twitter is a social media platform where individuals can express their thoughts freely and that government policies are rarely highly approved of. And if that were true, most of the tweets are negative, and the overall negative feedback was as expected, what do policy-makers take from that feedback and why pay any attention to public response on these large-scale, complex health policy issues?

To drill down further on responses, tweets were further separated into tweets classified as negative by VADER's sentiment analyzer, and LDA was applied on top of the negative tweets set for each jurisdiction. After positive tweets were removed, the Ontario dataset and the New York dataset had around 400,000 and 500,000 , respectively.

Top terms to each topic were captured using their calculated relevance (Equation 2) and interpreted alongside the OxCGRT. Note that the assigned relevance $(\lambda)$ for this project was .45 as mid-range relevance punishes terms that occur frequently across the corpus 6 . The Tracker provides four indices wherein policy responses, and the degree to which they are implemented within a jurisdiction, are logged over time. The indices are: the government response index, containment and health index, stringency index, and the economic support index. The indices are averages of individual component indicators, or factors, such as school closures ${ }^{7}$. For example, school closings contain the possible values of $0,1,2,3$, and blank, where 0 equals 'no measures', 1 equals 'recommended closings', 2 equals 'required closings at some levels', and 3 equals 'required closings at all levels'. Negative topics were interpreted under this lens, observations were recorded, and the possible impact for policy-makers was noted. Figure 1 demonstrates the high-level steps taken throughout the study to achieve observations and end results.

$$
\text { relevance }(\text { term } w \mid \text { topic } t)=\lambda * p(w \mid t)+(1-\lambda) * p(w \mid t) / p(w)
$$

(Equation 2)

\footnotetext{
${ }^{5}$ https://github.com/cjhutto/vaderSentiment\#about-the-scoring

${ }^{6}$ Sievert and Shirley (2014).

7 https://github.com/OxCGRT/covid-policy-tracker/blob/master/documentation/interpretation_guide.md
} 


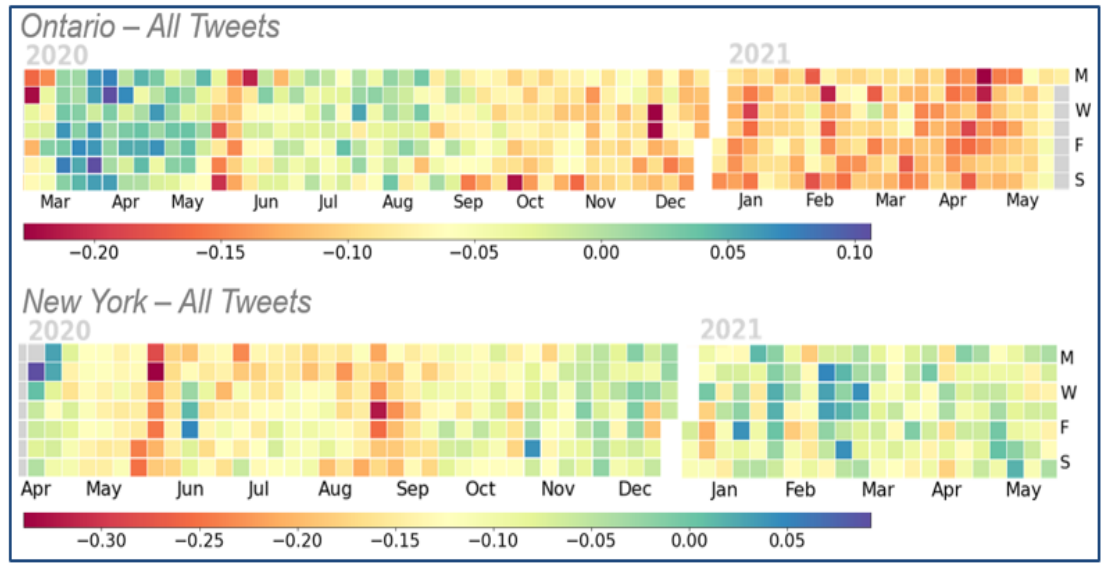

Figure 2. Ontario and New York's daily average sentiments (March 2020-June 2021)

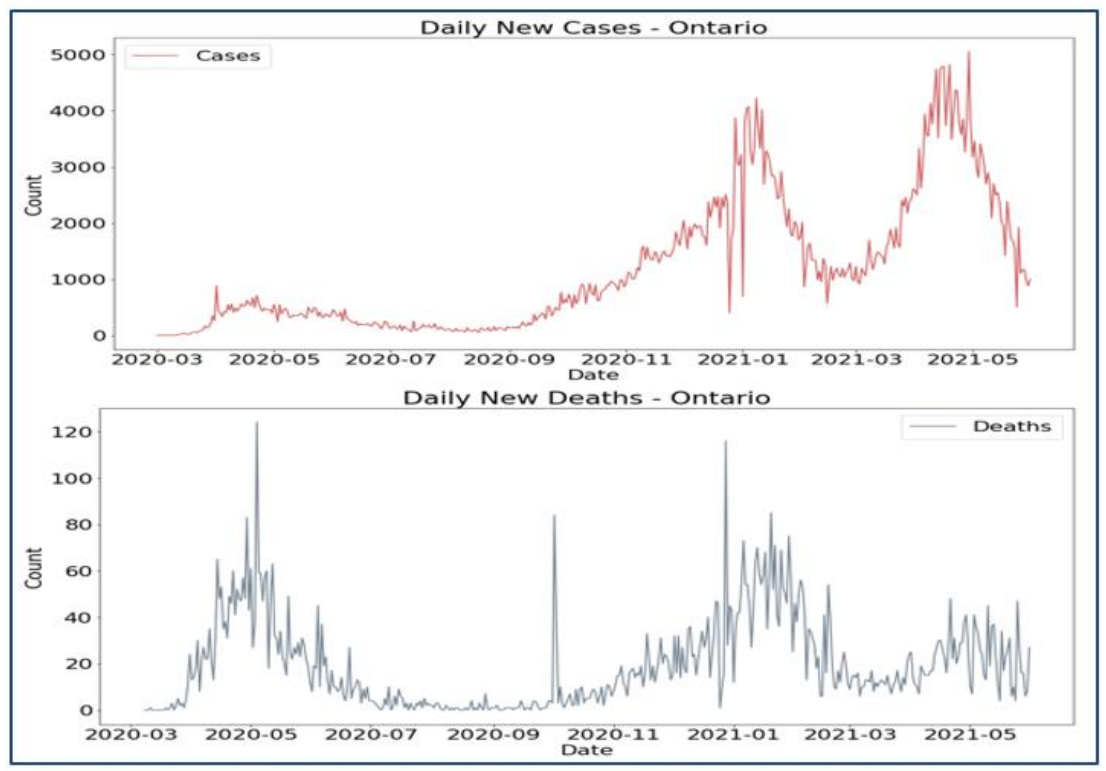

Figure 3. Ontario daily new case and death rates (March 2020-June 2020)

\section{RESULTS}

\section{Sentiment Analysis}

In this section, we will present the result of sentiment analysis for Ontario and New York. Figure 2 displays the average daily sentiments in the overall Ontario and New York datasets-after the neutral tweets were removed but before the positive tweets were removed. Both demonstrate fluctuations between periods where the daily average is positive sentiment and periods where the daily average is negative sentiment from March 2020 to June 2021. Within this visual, red demonstrates negative days and blue demonstrates positive days. 'MWFS' in the y-axis represents Monday, Wednesday, Friday, and Sunday, respectively. It is worth noting that the color gradient can is assigned by the overall distribution of figures within the given time period. If the range between figures is small, the calendar map could appear neutral or even positive even if the highest value in the set is negative. This gradient approach was chosen to better capture day-to-day fluctuations as it can be hard to see the differences between red and darker red, for example.

In Ontario, sentiments start out high and then bounce back to negative in Mid-May 2020-the same time period where the Government extended its first lockdown. Tweets get increasingly positive/neutral over the summer months when restrictions had eased and case rates were low (see Figure 3 ) and finally, tweets get increasingly negative over the colder months when containment \& health related restrictions started to tighten again, and case rates begin to build hitting peaks (see Figure 3) from November 2020-April 2021. 


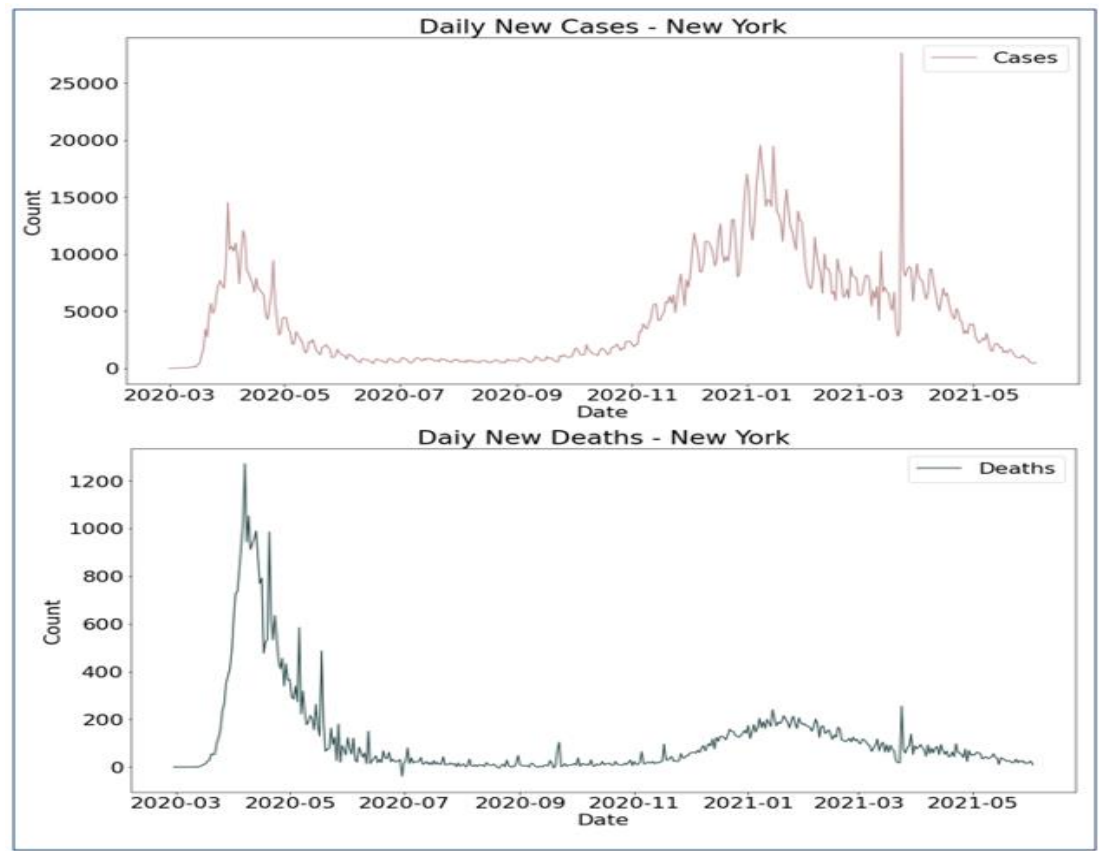

Figure 4. New York's daily new case and death rates (March 2020-June 2020)

New York shares a similar trend, however under much shorter durations. Positive tweets from lateOctober 2020-May 2021 align with decreasing case and death rates (see Figure 4) as well as the meaningful loosening of restrictions in late February (Figure 4).

The average daily sentiments reveal a pattern that aligns well with research done on attitudes expressed towards government in a pre vs. post-lockdown setting, which demonstrated that individuals felt higher levels of unity and support for their government's actions in the few first weeks following lockdown. In later months, average daily sentiments drop too almost exclusively negative. This also aligns with research done on policy fatigue, which found a strong relationship between waning public compliance to certain COVID-19 policies and time spent subjected to those policies. For New York, the daily average sentiment trend was somewhat the opposite-however, the daily case and death rates were also somewhat opposite to Ontario's-and the points that are most negative follow the largest new case and death peaks.

As mentioned above, the investigation of sentiments within original topics showed that tweets relating to COVID-19 were over-archingly negative, however, the discussions revealed lacked specificity. Further, topics within groups varied in terms of sentiment which left topics convoluted. Therefore, LDA was performed on negative tweets exclusively. The sentiments in the negative topic groups were far more negative and revealed differing day-to-day patterns (Figure 5 and Figure 6).

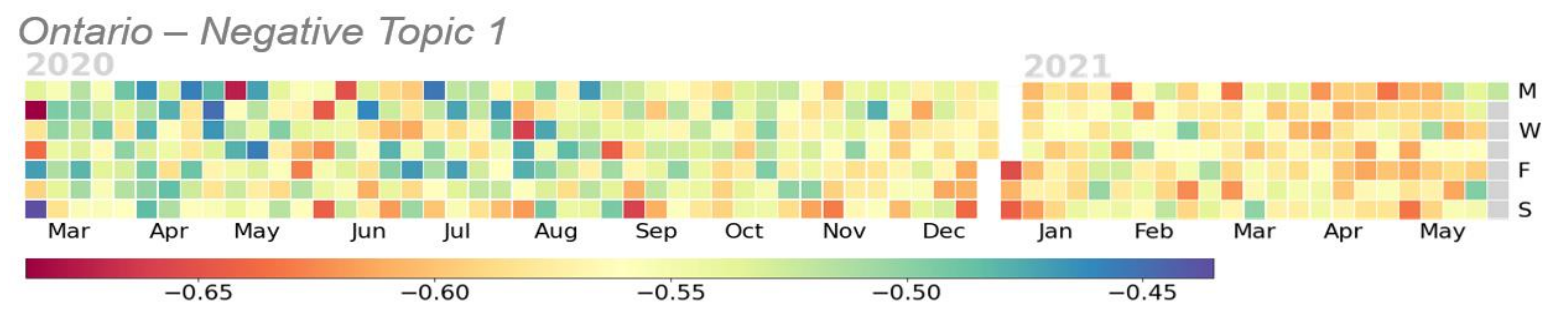

Ontario - Negative Topic 2

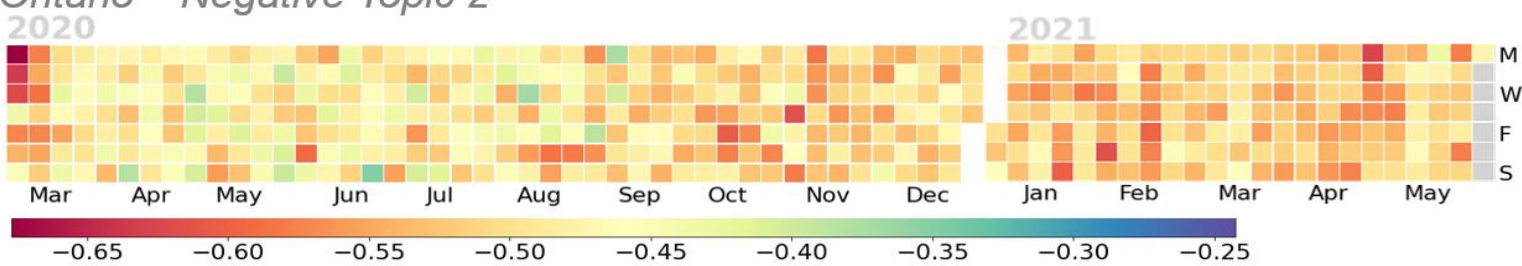

Figure 5. Ontario's negative topics' daily average sentiment changes over time 
Ontario - Negative Topic 3

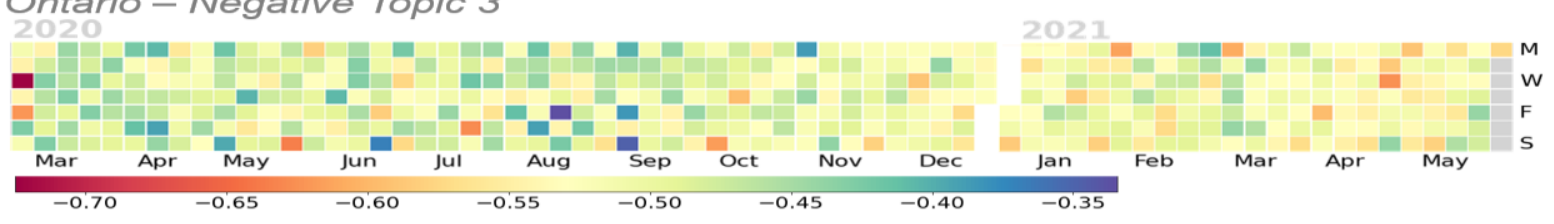

Ontario - Negative Topic 4

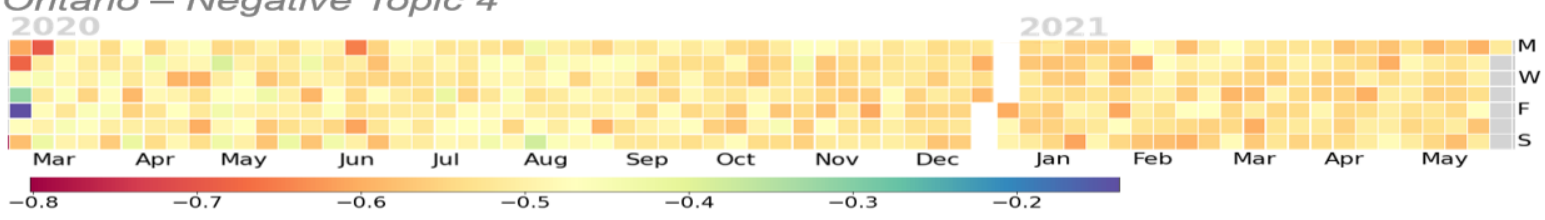

Ontario - Negative Topic 5

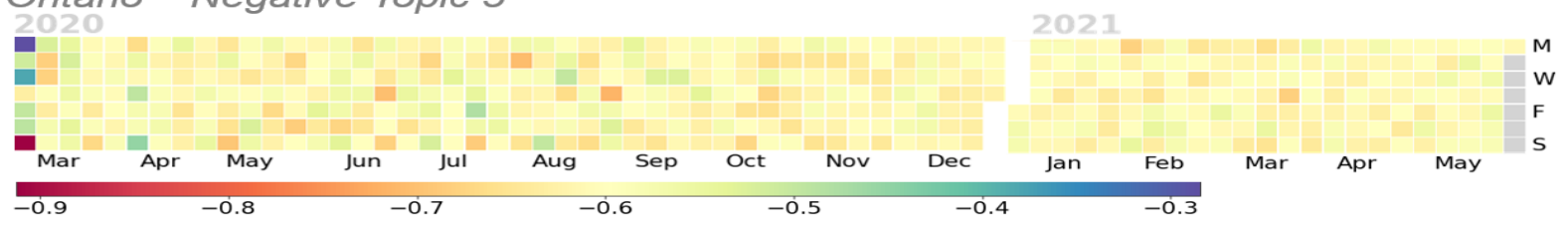

Figure 5 (continued). Ontario's negative topics' daily average sentiment changes over time

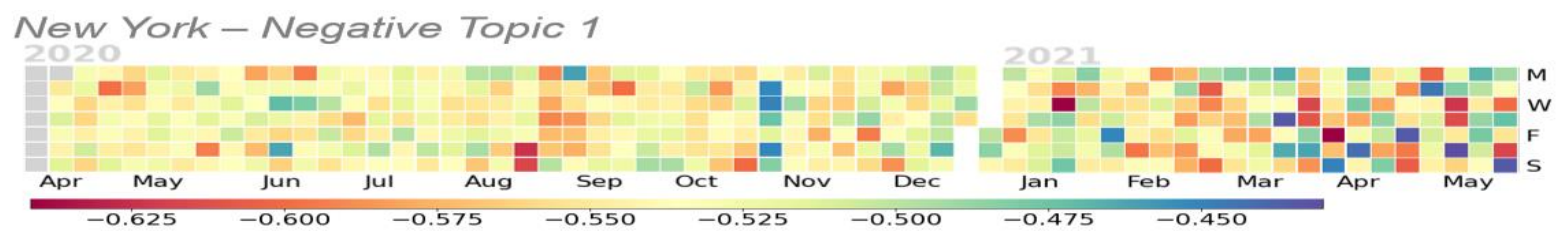

New York - Negative Topic 2

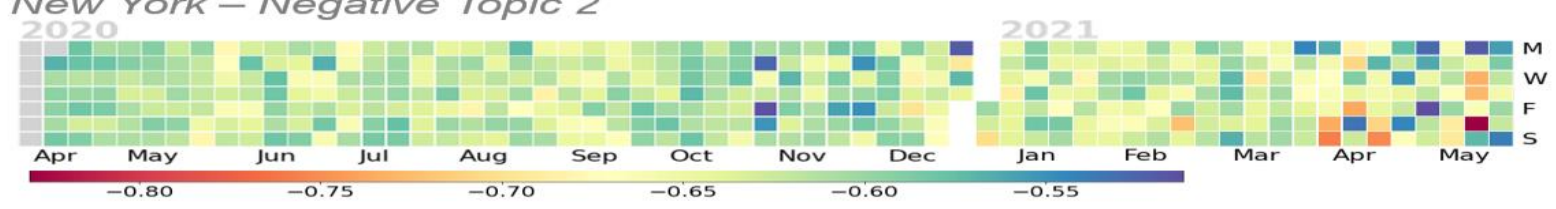

New York - Negative Topic 3

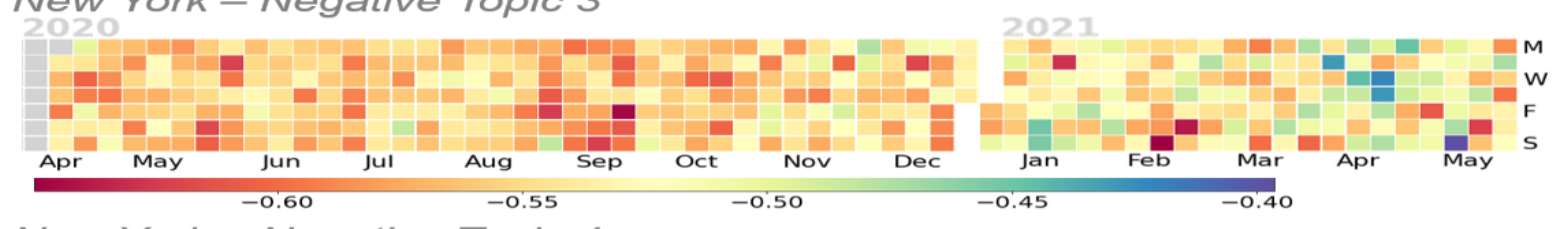

New York - Negative Topic 4

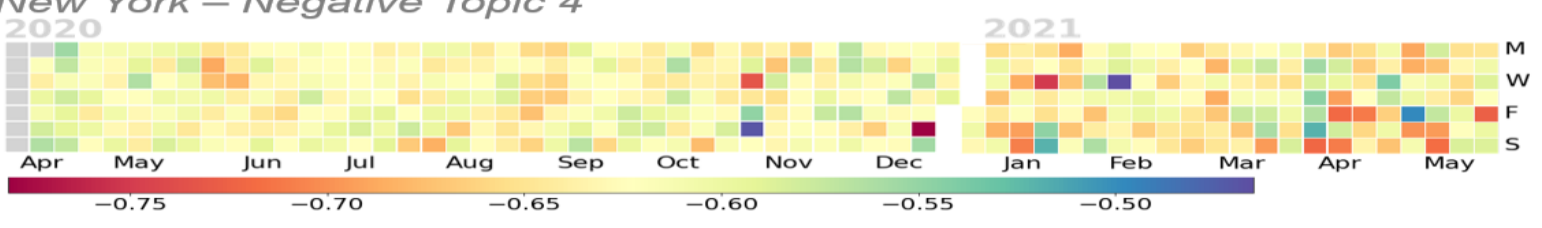

New York - Negative Topic 5

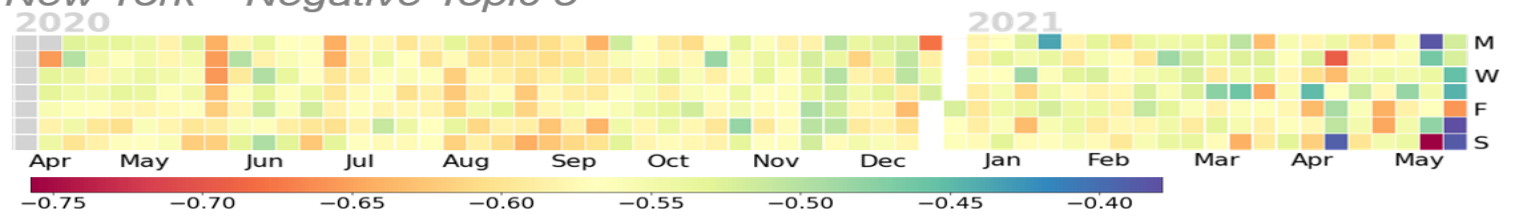

New York - Negative Topic 6

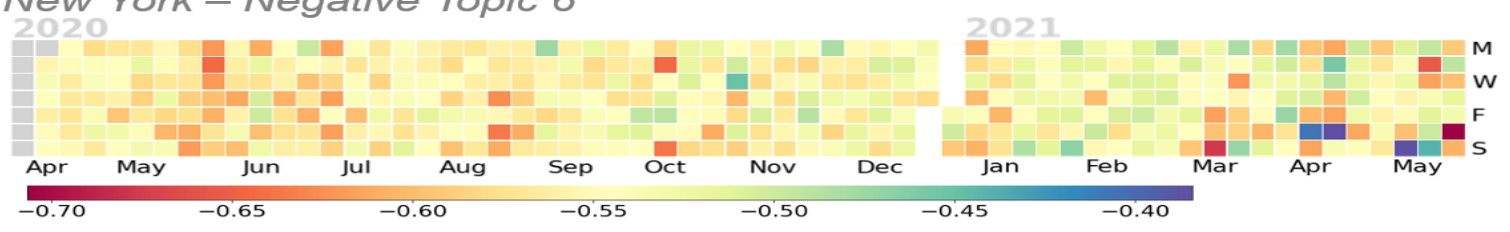

Figure 6. New York's negative topics' daily average sentiment changes over time 


\begin{tabular}{|c|c|c|}
\hline \multicolumn{2}{|c|}{$\begin{array}{l}\text { Ontario Topic } 1 \text { theme: } \\
\text { Government Response }\end{array}$} & Avg Sentiment: $\mathbf{- 0 . 5 5 5 9}$ \\
\hline \multicolumn{2}{|c|}{ Most Relevant terms } & Sentiment change: \\
\hline $\begin{array}{ll}\text { - } & \text { Pandemic } \\
\text { Government }\end{array}$ & $\begin{array}{ll}\text { - } & \text { Crisis } \\
\text { - Job }\end{array}$ & Most frequent trigrams: \\
\hline Ford & - Cut & - $\quad$ Pay sick days \\
\hline Fail & - Doug & - Cut pandemic help \\
\hline Money & - Ontarian & - Paid sick leave \\
\hline - Blame & - Govt & - Long term care \\
\hline Response & - Failure & - $\quad$ Premier Doug Ford \\
\hline
\end{tabular}

Figure 7. Ontario negative topic 1 summary

\section{Ontario Topic 2 theme: Containment / health}

\begin{tabular}{|c|c|}
\hline & \\
\hline $\begin{array}{ll}\text { - } & \text { death } \\
\text { - } & \text { Virus } \\
\text { - } & \text { Health } \\
\text { - } & \text { Die } \\
\text { - } & \text { Flu } \\
\text { - } & \text { Kill } \\
\text { - } & \text { rate }\end{array}$ & $\begin{array}{ll}\text { - } & \text { Cause } \\
\text { - } & \text { Lockdown } \\
\text { - } & \text { Fear } \\
\text { - } & \text { People die } \\
\text { - } & \text { Covid death } \\
\text { - } & \text { mental } \\
\text { - } & \text { Public health }\end{array}$ \\
\hline
\end{tabular}

Avg Sentiment: $\mathbf{- 0 . 5 0 2 7}$

\section{Sentiment change:}

Most frequent trigrams:

- Paid sick days

- Paid sick leave

- Need paid sick

- Negative covid test

- $\quad$ Going work sick

Figure 8. Ontario negative topic 2 summary

Most notably about these daily average sentiment trends over time for each topic is that they demonstrate that each topic has its own unique ebb and flows that often correspond to the content relevance at that specific time period. For example, New York's negative topic 2 seems pretty consistent over the duration of the captured tweets, however, most positive value in the set is -0.55 , and an overall daily average sentiment of -0.622 (remember -1 is most negative on the compound scale). The consistency across the calendar map suggests that individuals were consistently upset throughout this time period-which corresponds to the topic itself, being general pandemic anxiety and expression of concern. This will be discussed further in below.

\section{Topic Modeling and Interpretation}

Each of the negative topics from the Ontario and New York datasets are summarized and interpreted below. The summary captures each topic's most relevant terms (Sievert \& Shirley, 2014), most frequent trigrams, the overall average sentiment score, the trend of the sentiment score over time, and the most fitting OxCGRT indices theme. It is worth noting that the components included in each policy index can overlap, therefore, many of the trends will share jumps across indices, particularly if government approaches are done in packaged 'phases' where a battery of policies is imposed or removed.

Ontario's negative topic 1 focuses pretty firmly on the government's response to COVID-19. The most relevant terms are focused on the current government leadership, and key adjectives like fail, crisis, blame, response, and failure. Over the duration of the pandemic, Premier Doug Ford and his government were regularly and widely criticized for policies that lacked rationale or had long delays in implementation. In December 2020, it was uncovered that the Ontario Government was holding onto pandemic relief funds provided to them by the Federal Government ${ }^{8}$, which resulted in further public scrutiny (Figure 7).

Ontario's negative topic 2 reveals what could be described as general anger and pandemic anxiety. These concerns rely on a relationship with a tangible policy, such as paid sick leave, testing, and managing the spread. Research on crisis management and public response shows that, regardless of the circumstance, individuals get most upset about the case and death rates more so than any explicit policy (Figure 8).

\footnotetext{
8 https://toronto.ctvnews.ca/ontario-sitting-on-12b-in-unspent-covid-19-contingency-funding-at-start-of-second-wave-1.5221812
} 


\begin{tabular}{|c|c|c|}
\hline \multicolumn{3}{|c|}{ Ontario Topic 3 theme: } \\
\hline \multicolumn{2}{|c|}{ Most Relevant terms } & Sentiment change: \\
\hline $\begin{array}{ll}\text {. } & \text { Not } \\
\text { Work }\end{array}$ & $\begin{array}{l}\text { Hospital } \\
\text { Vaccine }\end{array}$ & Most frequent trigrams: \\
\hline - $\quad$ Test & - $\quad$ Need & - New covid cases \\
\hline Pay & Testing & Stay home order \\
\hline Sick & - Essential & - Premier Doug Ford \\
\hline - Know & Pay sick & People stay home \\
\hline Worker & Nurse & Science advisory table \\
\hline
\end{tabular}

Figure 9. Ontario negative topic 3 summary

\begin{tabular}{|c|c|c|}
\hline \multicolumn{3}{|c|}{ Ontario Topic 4 theme: } \\
\hline \multicolumn{2}{|c|}{ Most Relevant terms } & Sentiment change: \\
\hline - $\quad$ Spread & - $\quad$ Stop & Most frequent trigrams: \\
\hline - Mask & - Want & - $\quad$ Stop spread covid \\
\hline - People & - Live & - Smaller class sizes \\
\hline : $\quad$ Kid & . Wear & - Masks social distancing \\
\hline - Risk & - Teacher & - Masks don't work \\
\hline
\end{tabular}

Figure 10. Ontario negative topic 4 summary

\begin{tabular}{|c|c|c|}
\hline \multicolumn{3}{|c|}{ Ontario Topic 5 theme: } \\
\hline Most Relev & ant terms & Sentiment change: \\
\hline 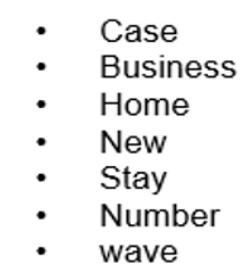 & $\begin{array}{ll}\text { : } & \text { Stay home } \\
\text { : } & \text { Small } \\
\text { : } & \text { Travel } \\
\text { : } & \text { Shut } \\
\text { : } & \text { Country } \\
\text { : } & \text { Smaller business }\end{array}$ & 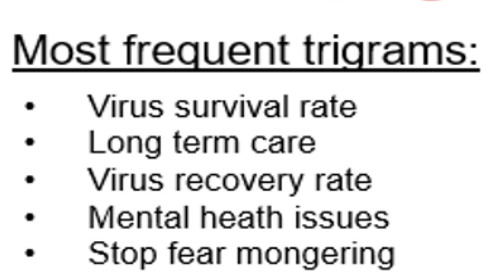 \\
\hline
\end{tabular}

Figure 11. Ontario negative topic 5 summary

Ontario's negative topic 3 top discussions center on economic-related issues. Essential workers, small businesses, and paid sick leave were ongoing issues throughout the duration of the pandemic in Ontario. Government communications of policies were high-level and vague, often resulting in confusion for businesses and essential workers (Figure 9).

Ontario's negative topic 4 hones in on the Ontario Government's policies regarding schools. A major source of media attention and discussion surrounded the flip-flop nature of the Government's policy, which required school/class closures after a positive COVID-19 test. Furthering issues was the policy that required parents to keep their school-age children home from school if they had certain symptoms, such as a running nose. This policy put a lot of pressure on parents who were working from home particularly working mothers, to attend to their child's schooling at home while balancing work and other household demands (Figure 10).

Ontario's negative topic 5 is unexpected and focused largely on rules that pertain to the federal jurisdiction. For example, all travel bans, and border closures are the business of the federal government. Small businesses were impacted by border closures and faced difficulties in the early stages of the pandemic due to a widespread shortage of secondary manufactured goods (Figure 11). 


\begin{tabular}{|c|c|c|}
\hline $\begin{array}{l}\text { New York Topic } \\
\text { Containment I }\end{array}$ & $\begin{array}{l}1 \text { theme: } \\
\text { Health }\end{array}$ & Avg Sentiment: $\mathbf{- 0 . 5 3 5 1}$ \\
\hline Most Relevant & terms & Sentiment change: \\
\hline · Home & $\begin{array}{ll}\text { - } & \text { Elderly } \\
\text { - } & \text { Cuomo }\end{array}$ & Most frequent trigrams: \\
\hline Nursing & Thousand & Masks social distancing \\
\hline Nursing home & Hospital & - Masks don't work \\
\hline - Patient & - Force & - Don't wear mask \\
\hline $\begin{array}{ll}\text { - } & \text { Kill } \\
\text { Covid patient }\end{array}$ & $\begin{array}{ll}\text { - } & \text { Order } \\
\text { senior }\end{array}$ & $\begin{array}{ll}\text { - } & \text { Stop spread virus } \\
\text { Virus survival rates }\end{array}$ \\
\hline
\end{tabular}

Figure 12. New York negative topic 1 summary

\begin{tabular}{|c|c|c|}
\hline & $\begin{array}{l}\text { New York Topic } \mathbf{2} \text { theme: } \\
\text { Government Response Avg Sentiment: } \mathbf{- 0 . 6 2 2 6}\end{array}$ \\
\hline & Most Relevant terms $\quad$ Sentiment change: (4y \\
\hline \multicolumn{3}{|c|}{$\begin{array}{llll}\text { - Trump } & \text { World } & \text { Moax } & \text { Most frequent trigrams: } \\
\text { Lie } & \text { Hoam }\end{array}$} \\
\hline Blame & Americans & - People die covid \\
\hline - President & Fuck & Americans died covid \\
\hline - China & - Ass & Virus came china \\
\hline $\begin{array}{ll}\cdot & \text { Dead } \\
& \text { Country }\end{array}$ & $\begin{array}{ll}- & \text { Fake } \\
\text { - } & \text { Attack }\end{array}$ & $\begin{array}{l}\text { - Patients nursing home } \\
\quad \text { Called virus hoax }\end{array}$ \\
\hline
\end{tabular}

Figure 13. New York negative topic 2 summary

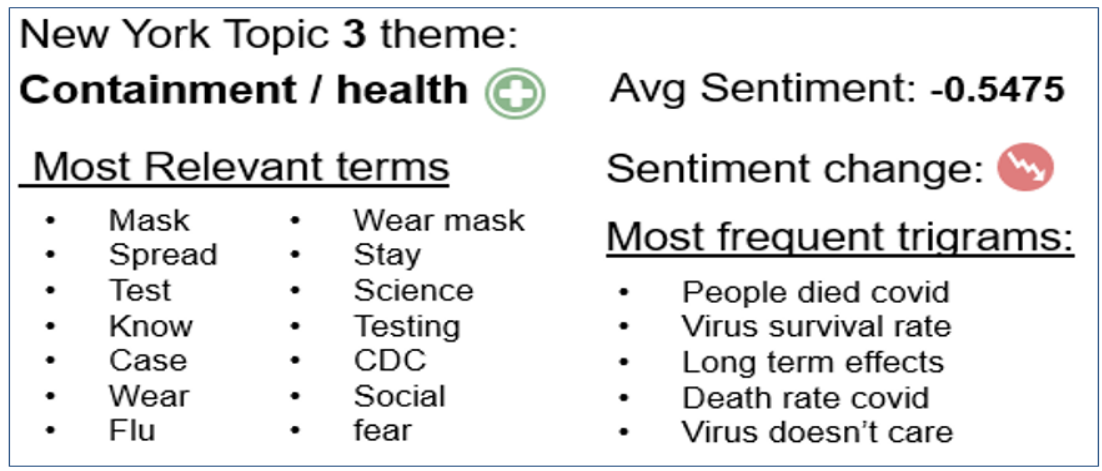

Figure 14. New York negative topic 3 summary

New York's negative topic 1 could be related strictly to the scandal wherein the Government of New York was discovered for purposely misreporting case and death rates in long-term care settings ${ }^{9}$. It was discovered not long after the pandemic peak in New York that the numbers were higher in reality, obviously sparking public outrage. This scandal was tied to former Governor Cuomo's office-this incident alongside allegations of sexual misconduct led to his resignation in the late spring (Figure 12).

New York's negative topic 2 is unexpected and appears to be concerned with foreign policy related to the pandemic and the former president of the United States. It is also the only topic that identified discussions related to conspiracy theories, such as the pandemic being a hoax and the only topic that had profanity in its most relevant terms. Overall, the topic is focused on the frustrations of individuals who may be concerned with the government's approach for reasons based on non-reality (Figure 13).

New York's negative topic 3 appears to be the flipside of the previous topic. The focus is on science, CDC, wearing masks, and over-archingly containing the spread of the virus. An interesting observation is that the trigrams are very similar between this topic and the previous topic (Figure 14).

\footnotetext{
${ }^{9}$ https://www.bbc.com/news/world-us-canada-56091682
} 


\begin{tabular}{|c|c|c|}
\hline \multicolumn{3}{|c|}{ New York Topic 4 theme: } \\
\hline \multirow{2}{*}{\multicolumn{2}{|c|}{$\begin{array}{l}\text { Containment / health } \\
\text { Most Relevant terms }\end{array}$}} & Avg Sentiment: $\mathbf{- 0 . 6 2 3 2}$ \\
\hline & & Sentiment change: (y) \\
\hline $\begin{array}{l}\text { - } \text { State } \\
\text { - NYC }\end{array}$ & $\begin{array}{ll}\text { - } & \text { Governor } \\
\text { - } & \text { Leadership }\end{array}$ & Most frequent trigrams: \\
\hline - $\quad$ City & - Failure & - $\quad$ Patients nursing homes \\
\hline - Mayor & - $\quad$ Police & Covid patients nursing \\
\hline - Response & - Crisis & - Nursing homes covid \\
\hline Fail & Daily & - People nursing homes \\
\hline Handle & crime & - Covid positive patients \\
\hline
\end{tabular}

Figure 15. New York negative topic 4 summary

\begin{tabular}{|c|c|c|}
\hline \multicolumn{3}{|c|}{ New York Topic 5 theme: } \\
\hline Most Relevar & at terms & Sentiment change: \\
\hline $\begin{array}{l}\text { - Help } \\
\text { - } \quad \text { Pay }\end{array}$ & $\begin{array}{ll}\text { - } & \text { Pass } \\
\text { Unemployn }\end{array}$ & Most frequent trigrams: \\
\hline - Money & Cut & New York city \\
\hline Plan & Worker & - New York state \\
\hline - $\quad$ Need & - Relief & - Nyc mayor Blasio \\
\hline $\begin{array}{ll}\text { - } & \text { Government } \\
\text { - } & \text { Fight }\end{array}$ & $\begin{array}{l}\text { Job } \\
\text { tax }\end{array}$ & $\begin{array}{l}\text { - New Yorkers died } \\
\text { - } \quad \text { Let covid ambush }\end{array}$ \\
\hline
\end{tabular}

Figure 16. New York negative topic 5 summary

\begin{tabular}{|c|c|c|}
\hline \multicolumn{3}{|c|}{ New York Topic 6 theme: } \\
\hline Most Rele & t terms & Sentiment change: \\
\hline $\begin{array}{ll}\text { - } & \text { Not } \\
\text { - } & \text { People } \\
\text { - } & \text { Covid } \\
\text { - } & \text { Rate } \\
\text { - } & \text { Care } \\
\text { - } & \text { School } \\
\text { - } & \text { Risk }\end{array}$ & $\begin{array}{ll}\cdot & \text { Problem } \\
\text { - } & \text { Child } \\
\text { - } & \text { Business } \\
\text { - } & \text { Live } \\
\dot{\text { - }} & \text { Community } \\
\text { - } & \text { Kid } \\
\text { - } & \text { Infection }\end{array}$ & \begin{tabular}{ll}
\multicolumn{2}{l}{ Most frequent trigrams: } \\
: & New York city \\
- & New York state \\
- & Nyc mayor Blasio \\
: & New Yorkers died \\
- & Let covid ambush
\end{tabular} \\
\hline
\end{tabular}

Figure 17. New York negative topic 6 summary

New York's negative topic 4 appears to be more strictly about government leadership throughout the pandemic and shares some similarities with the first topic. It is worth mentioning that this topic had a number of trigrams that mentioned the rights of black Americans or people of color. This topic may be more highlevel, and less about the pandemic as much as the government leadership failures in and of itself (Figure 15).

New York's negative topic 5 refers to economic issues, such as government support for workers, taxes, and general COVID-19 relief. This is surprising given the economic relief in the United States was substantial comparatively. In any case, many individuals lost their jobs (Figure 16).

New York's negative topic 6 shares some similarities with Ontario's topic 4-both focus on schools and childcare. New York had a similar flip flop issue to Ontario, which lead to confusion and anger amongst the public (Figure 17). 


\section{DISCUSSION}

As discussed previously, the way in which a government implements its policy decisions has an impact on the public compliance to those policies. Communication is an essential part of all policy implementation, particularly as it relates to public health matters. The further communication is tailored the more successful one can expect a policy solution to be, both in terms of dissemination and overall compliance. In crisis, governments have little time to understand how their policy decisions impact the public. The approach used in this study could support governments in the design stage of policy communication by providing the insights needed to tailor outreach for different communities.

The findings of this study showed that the discussion topics within the two jurisdictions had different content, however, the overarching concerns were still similar-most tweets referred to the general public health impact, e.g., the case rates and death rates throughout the duration of the pandemic. This is realized in many ways-for example, in New York, the top discussions referred to nursing homes and the safety of elders in those living settings. Whereas in Ontario, the issue of spread and survival rates comes up often. While this observation seems sort of obvious, it serves an important benchmark for governments in terms of understanding the audience they are addressing. Sentiments change significantly overtime, as shown in this study and others (Sibley et al., 2020) and therefore communication style should develop accordingly to mitigate policy fatigue and public outrage.

This study demonstrated that the same policies are discussed across sentiment (and presumably political) spectrums and between topic groups. However, it also found that the policy outcomes of the same policies are understood differently within each topic. Both jurisdictions in this study demonstrated a frustration with their governments' competency or the impact of a particular policy and that policies success in combating the pandemic. As can be observed between the topics, some issues arise across topic groups frequently. However, the most relevant terms to those topic groups can be very much the opposite despite this mutual ground. For example, the policy of wearing masks in some topics related masks to saving lives, but in some subgroups the same policy of wearing masks was contributed to deaths. It is recognized in this study that these negative tweets are not always descriptive as to why the individual is upset with, nor what that person's personal experience with the policy is (if at all), but the variation in understanding of the same policy's outcome can suggest that communication of certain aspects of a policy are not clear to certain groups. Therefore, further leveraging discussions related to policies that experience large variation in sentiment could provide grounds to better tailor solutions that would yield less variation in understanding.

Finally, the indices and topics support early/mid research regarding COVID-19 policy and public response. The closest we get to the 'why' factor in people's negative sentiment is the observation that many frequent terms within topics demonstrate frustrations with the rationale or delay of a policy. This observation would suggest that the way in which a policy is delivered, which requires large aspects of communication, has a significant impact on the sentiments expressed towards it and not necessarily the policy itself.

Overall, the observations of this study align with recent research on COVID-19 policy and governments' crisis management. Particularly, research on the public response towards government policy and public compliance, which discussed how all individuals experience policy fatigue, high-impact policies are more likely to experience fatigue and non-compliance under shorter durations, and that people were most upset with case and death rates. As will be discussed below, these insights are important stepping stones to improving policy design and delivery.

\section{CONCLUSIONS}

This study aimed to identify specific topics and relationships that would support policy-makers in interpreting their audience in real-time. Twitter data, a variety of python libraries, and a focus on relevance were used to achieve specific topic groups for the sample datasets (Ontario and New York). The study found that first, the most frequent and most passionate tweets across both sets were made with respect to case and death rates in individuals' jurisdictions. This supports previous research on crisis management (Chen et al., 2021; Sabat et al., 2020; Sibley et al., 2020) and is important to note because one can discern from there what policies or actions individuals associate with case and death rates. With some issues, for example, masks 
or vaccines, individuals associate the lack of a policy with high death rates and on the other side of the spectrum, individuals associate their perceived high stringency of the same policy with high death rates. And second, the study determined that many tweets expressed frustrations with the communication, length of implementation, or lack of rationale behind policies. This finding is also in line with previous research on policy fatigue (Petherick et al., 2021) and suggests that the way the policy is communicated and delivered impacts individuals' sentiments toward the policy more than the policy itself.

The study has a few limitations, most notably being the method for classifying sentiments. While VADER's sentiment analyzer is strong at detecting direct social media text, it did not seem to be particularly successful at detecting sarcasm. The use of sarcastic emojis has become quite popular and can override negative expressions or vice versa. For example, the use of the crying laughing face can out way negative criticism in the same text, turning the overall score positive as opposed to negative. Therefore, using more advanced methods to classify sentiments, or even using emotion classification can be expected to enhance the results.

Further, it is known that twitter is susceptible to bots, which could alter the outcomes observed or true sentiment of a topic. There is plenty of research into how to identify and extract these tweets, and one could expect results to be more reliable if those models were used as a pre-processing step.

It is also worth highlighting the use of government handles as an approximation for the location of tweets. The idea was that individuals weren't likely to tweet at a government official concerning a policy unless that policy directly impacts them. Of course, this is an assumption, however as mentioned, very few tweets have geolocation and geo-tagged tweets are not reliable.

Next, the study employed an almost hierarchical approach two topic modeling which was effective in digging into issues further to discover subjects of interest and relationships. However, through this investigation, it appears that a more flexible solution may better bring out the relationships and overlapping tendencies of topic areas.

Finally, research shows that the preprocessing steps used can impact the outcomes of machine learning approaches to the classification of text data (Kaminska et al., 2021). Given resource limitations, and the desire to keep the study solution accessible, term frequency-inverse document frequency vectorization of text was used. However, word2vec based models have been shown to be more effective in preserving the important syntactic details of text data.

Research in this area is important because an individual's compliance with public health policies shares a relationship with the attitudes expressed towards those policies. This data and study leave a good jumpingoff point to dig further into the relationships between topics and subject matter. A graphical approach may reveal interesting patterns or connections that were not determined concretely in this study. Employing solutions that grapple with the above limitations may assist individuals in achieving higher certainty of their results, which may set a stage for answering larger questions such as how policy-makers can better leverage social media when framing policy efficacy investigations and how to accurately weigh public responses against policy delivery efforts. Further identifying discussions, relationships, and more accurately characterizing the average sentiment expressed within those discussions will support government in grounding their policy communication, education, or reform.

Author contributions: All authors were involved in concept, design, collection of data, interpretation, writing, and critically revising the article. All authors approve final version of the article.

Funding: The authors received no financial support for the research and/or authorship of this article.

Declaration of interest: Authors declare no competing interest.

Data availability: Data generated or analyzed during this study are available from the authors on request.

\section{REFERENCES}

Albalawi, Y., Carroll, N., \& Nikolov, N. S. (2017). Opportunities for social media to support health communication in health crises. In The 3rd European Technology Assessment Conference.

Arpaci, I., Alshehabi, S., Al-Emran, M., Khasawneh, M., Mahariq, I., Abdeljawad, T., \& Hassanien, A. E. (2020). Analysis of Twitter data using evolutionary clustering during the COVID-19 pandemic. Computers, Materials \& Continua, 65(1), 193-204. https://doi.org/10.32604/cmc.2020.011489 
Chen, C. W., Lee, S., Dong, M. C., \& Taniguchi, M. (2021). What factors drive the satisfaction of citizens with governments' responses to COVID-19? International Journal of Infectious Diseases, 102, 327-331. https://doi.org/10.1016/j.jij.2020.10.050

Dey, R. K., Sarddar, D., Sarkar, I., Bose, R., \& Roy, S. (2020). A literature survey on sentiment analysis techniques involving social media and online platforms. International Journal of Scientific \& Technology Research, 9(5), 166-173.

Hutto, C., \& Gilbert, E. (2014). Vader: A parsimonious rule-based model for sentiment analysis of social media text. In Proceedings of the International AAAl Conference on Web and Social Media (pp. 216-225). https://ojs.aaai.org/index.php/ICWSM/article/view/14550

Jelodar, H., Wang, Y., Orji, R., \& Huang, S. (2020). Deep sentiment classification and topic discovery on novel coronavirus or COVID-19 online discussions: NLP using LSTM recurrent neural network approach. IEEE Journal of Biomedical and Health Informatics, 24(10), 2733-2742. https://doi.org/10.1109/JBHI.2020. 3001216

Kaila, R. P., \& Prasad, A. V. K. (2020). Informational flow on Twitter-Corona virus outbreak-topic modelling approach. International Journal of Advanced Research in Engineering and Technology, 11(3), 128-134.

Kaminska, O., Cornelis, C., \& Hoste, V. (2021). Fuzzy-rough nearest neighbour approaches for emotion detection in tweets. In International Joint Conference on Rough Sets (pp. 231-246). Springer, Cham. https://doi.org/10.1007/978-3-030-87334-9_20

Müller, M., Salathé, M., \& Kummervold, P. E. (2020). COVID-Twitter-BERT: A natural language processing model to analyse COVID-19 content on Twitter. arXiv preprint arXiv:2005.07503. https://doi.org/10.48550/ arXiv.2005.07503

Petherick, A., Goldszmidt, R., Andrade, E. B., Furst, R., Pott, A., \& Wood, A. (2021). A worldwide assessment of COVID-19 pandemic-policy fatigue. SSRN 3774252. https://doi.org/10.2139/ssrn.3774252

Roy, M., Moreau, N., Rousseau, C., Mercier, A., Wilson, A., \& Atlani-Duault, L. (2020). Ebola and localized blame on social media: Analysis of Twitter and Facebook conversations during the 2014-2015 Ebola epidemic. Culture, Medicine, and Psychiatry, 44(1), 56-79. https://doi.org/10.1007/s11013-019-09635-8

Sabat, I., Neuman-Böhme, S., Varghese, N. E., Barros, P. P., Brouwer, W., van Exel, J., Schreyögg, J., \& Stargardt, T. (2020). United but divided: Policy responses and people's perceptions in the EU during the COVID-19 outbreak. Health Policy, 124(9), 909-918. https://doi.org/10.1016/j.healthpol.2020.06.009

Sanders, A. C., White, R. C., Severson, L. S., Ma, R., McQueen, R., Paulo, H. C. A., Zhang, Y., Ercikson, J. S., \& Bennett, K. P. (2021). Unmasking the conversation on masks: Natural language processing for topical sentiment analysis of COVID-19 Twitter discourse. AMIA Joint Summits on Translational Science Proceedings, 2021, 555-564. https://doi.org/10.1101/2020.08.28.20183863

Sarsam, S. M., Al-Samarraie, H., Alzahrani, A. I., Alnumay, W., \& Smith, A. P. (2021). A lexicon-based approach to detecting suicide-related messages on Twitter. Biomedical Signal Processing and Control, 65, 102355. https://doi.org/10.1016/j.bspc.2020.102355

Satu, Md. S., Khan, Md. I., Mahmud, M., Uddin, S., Summers, M. A., Quinn, J. M. W., \& Moni, M. A. (2021). TClustVID: A novel machine learning classification model to investigate topics and sentiment in COVID19 tweets. Knowledge-Based Systems, 226, 107126. https://doi.org/10.1016/j.knosys.2021.107126

Sibley, C. G., Greaves, L. M., Satherley, N., Wilson, M. S., Overall, N. C., Lee, C. H. J., Milojev, P., Bulbulia, J., Osborne, D., Milfont, T.L., Houkamau, C. A., Duck, I. M., Vickers-Jones, R., \& Barlow, F. K. (2020). Effects of the COVID-19 pandemic and nationwide lockdown on trust, attitudes toward government, and wellbeing. American Psychologist, 75(5), 618-630. https://doi.org/10.1037/amp0000662

Sievert, C., \& Shirley, K. (2014). LDAvis: A method for visualizing and interpreting topics. In Proceedings of the Workshop on Interactive Language Learning, Visualization, and Interfaces (pp. 63-70). https://doi.org/10. 3115/v1/W14-3110

Vashishtha, S., \& Susan, S. (2021). Highlighting keyphrases using senti-scoring and fuzzy entropy for unsupervised sentiment analysis. Expert Systems with Applications, 169(2), 114323. https://doi.org/10. 1016/j.eswa.2020.114323
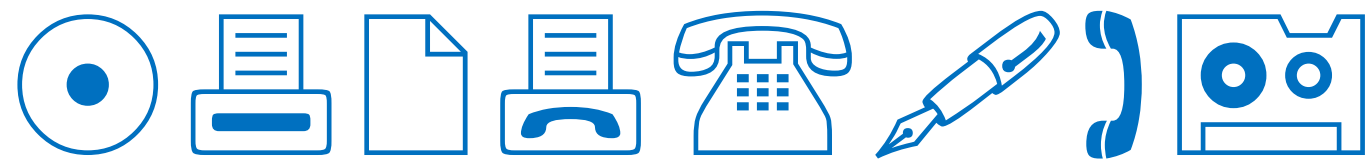